\title{
Vulnerabilidade das águas subterrâneas na região semiárida da Bahia, município de Tucano, pelo método GOD
}

Yuri dos Santos Nascimento ${ }^{1}$

Janisson Batista de Jesus²

Ricardo Lacerda Gomes ${ }^{3}$

\section{Resumo}

As atividades humanas podem promover a contaminação dos aquíferos, comprometendo a qualidade das águas subterrâneas. Por isso, é importante mapear os riscos de vulnerabilidade dos ambientes naturais, um dos métodos mais utilizados para tanto é o GOD (sigla de Groundwater occurrence; Overall aquifer class; Depth to groundwater). Sendo assim, o presente trabalho tem o objetivo de analisar a vulnerabilidade à contaminação dos aquíferos do município de Tucano utilizando o método GOD. Para o estudo foram analisados dados geológicos e hidrogeológicos de 449 poços tubulares obtidos no banco de dados SIAGAS (CPRM). O parâmetro G foi definido na maioria da área como aquífero não confinado, o parâmetro 0 recebeu valores entre 0,4 e 0,8 (devido à variação da composição litológica ao longo da área) e o parâmetro $D$, correspondente à profundidade do nível estático ficou entre 0,6 e 0,9, indicando um lençol freático superficial. 0 método GOD indicou a ocorrência de quatro classes de vulnerabilidade: insignificante $(1,28 \%)$, baixa $(71,99 \%)$, média $(23,79$ $\%$ ) e alta (2,94 \%). Verificou-se que o município de Tucano, na maior parte do território, possui uma vulnerabilidade baixa a média, indicando um baixo risco de contaminação do aquífero, tendo apenas na porção do Rio Itapicuru um índice apontando alta vulnerabilidade.

Palavras-chave: Aquífero. Contaminação. Geoprocessamento.

\section{Introdução}

Cerca de 97 \% da água doce disponível para o uso humano pode ser encontrada nas camadas subterrâneas (MEIRA et al., 2014), entretanto, a qualidade natural dessas reservas hídricas podem estar em risco devido à sua exploração excessiva, à irregular ocupação do solo e ao descumprimento da legislação (RIBEIRO et al., 2011). Isso pode ser resultante de eventuais lançamentos de poluentes ocorridos na superfície do solo que, tendo um meio favorável de infiltração e percolação, podem atingir os aquíferos (BATISTA et al., 2016).

Por serem geralmente de boa qualidade, 39\% dos municípios brasileiros captam as águas subterrâneas para abastecimento por meio de poços tubulares. No Estado da Bahia, 78 cidades são abastecidas unicamente por essa fonte hídrica e outras 32 utilizam-na como complemento ao abastecimento (ANA, 2010).

1 Faculdade Dom Luiz de Orleans e Bragança, engenheiro civil. yuri.dnsantos@gmail.com. BR 110, Km 7, Pombalzinho, Ribeira do Pombal (BA), CEP: 48.400-000.

2 Universidade Federal do Rio Grande do Sul, Programa de Pós-Graduação em Sensoriamento Remoto, janisson.eng@gmai.com.

3 Universidade Federal da Bahia, ricardolacerda12@hotmail.com. 
No município de Tucano, localizado no nordeste baiano, há uma malha de poços tubulares registrada no Sistema de Informações de Água Subterrânea (SIAGAS, 2016) do Serviço Geológico do Brasil (Companhia de Recursos Minerais - CPRM). Esses poços são destinados ao uso doméstico, industrial ou comercial, à dessedentação animal, entre outros (VIEIRA et al., 2005). Além disso, as águas subterrâneas neste município por serem águas termais têm uma importância turística primordial para a região semiárida e geram renda e desenvolvimento para a localidade. Devido à grande utilização desse tipo de fonte hídrica, é importante a fiscalização do padrão qualitativo e quantitativo dessas águas, uma vez que poços que não têm monitoramento podem se tornar vias de contaminação da água subterrânea, afetando a qualidade da água existente no aquífero (FERON; REGINATO, 2014).

De acordo com Feron e Reginato (2014), existem fatores de ordens distintas que devem ser não somente integrados, mas analisados a fim de avaliar a vulnerabilidade dos aquíferos. Esses fatores podem ser naturais (cobertura de solos, existência de camadas confinadas, estrutura e composição das rochas, entre outros) ou não naturais, de acordo com Marquezan (2008). Estes, por sua vez, ocorrem por meio da intervenção humana em pontos de considerável contaminação onde não há adequado controle. Assim, atividades agrícolas, industriais, urbanas e de mineração poluem por emissão e lixiviados, favorecendo o excesso da capacidade de atenuação natural dos solos das camadas de cobertura (FOSTER et al., 2006).

0 ideal é visar à manutenção da qualidade das águas subterrâneas por meio de análises da vulnerabilidade e do risco de contaminação, para identificar regiões que exibem distintos riscos de impurezas (REGINATO; AHLERT, 2013). Um dos métodos mais utilizados nessas análises é o método de GOD, sigla definida pelas iniciais que compõem cada fase: Groundwater occurrence, Overall aquifer class, Depth to groundwater. A metodologia proposta por este método, além de ser muito utilizada, serve para guiar a ocupação do solo, evitando áreas que possam ter maior potencial de contaminação dos aqüíferos, auxiliando, assim, na gestão dos recursos hídricos (SANTOS et al., 2013).

O método GOD de avaliação da vulnerabilidade do aquífero à contaminação é de simples aplicação e foi amplamente experimentado na década de 1990 no Caribe e na América Latina (FOSTER et al., 2006), sendo muito utilizado no Brasil (SOUZA et al., 2004, MONTEIRO; PEIXOTO, 2013, TERRA et al., 2013, DUARTE et al., 2016, SABADINI et al., 2017).

Logo, ao considerar o potencial risco de contaminação dos aquíferos em conjunto com a atividade antrópica de exploração, o presente trabalho foi realizado com o objetivo de analisar a vulnerabilidade das águas subterrâneas do município de Tucano, estado da Bahia, à contaminação, utilizando o método GOD.

\section{Material e métodos}

\section{Área de estudo e obtenção dos dados}

O estudo foi realizado no município de Tucano, Bahia, com área total de $2.817,74 \mathrm{~km}^{2}$ e localizado entre as coordenadas UTM (X/Y): 552151,32/8740373,09 e 482422,268/8817963,622, no nordeste baiano, na porção central da Bacia Hidrográfica do Rio Itapicuru, situado na região climática semiárida, com chuvas anuais inferiores a $700 \mathrm{~mm}$, cobertura vegetal com predomínio de pastagens entremeadas por áreas com vegetação de Caatinga (INSTITUTO ESTADUAL DO MEIO AMBIENTE E RECURSOS HÍDRICOS, 2017) e com os solos do tipo: Latossolo, Planossolo e Vertissolo, sendo 
esses os mais característicos no município (EMPRESA BRASILEIRA DE PESQUISA AGROPECUÁRIA, 2006).

Os dados de profundidade (nível estático do lençol freático) e composição litológica de cada poço, de um total de 449, bem como de litologia da área de estudo, foram adquiridos pelo sítio do Serviço Geológico do Brasil (CPRM, 2017), por meio do Sistema de Informações de Águas Subterrâneas (SIAGAS) e do sistema Dados, que, por sua vez, fornece dados sobre os poços no Brasil, que foram utilizados para o presente estudo de uma série temporal de 01/01/1938 a 10/08/2013.

\section{Método GOD}

O método GOD é dividido em três fases (grau de confinamento da água subterrânea, característica do estrato de cobertura do aquífero e profundidade do nível freático) e considera diferentes condicionantes que determinam um maior ou menor potencial de vulnerabilidade do aquífero (FIGURA 1) a partir das características de cada aquífero; para cada característica foi atribuído um "peso" específico de acordo com a sua composição, associada ao verificado no município de Tucano.

Os dados de ligotipos e litologia foram utilizados para definir o grau de confinamento e os estratos de cobertura e foram convertidos em arquivo matricial Raster e atribuídos os valores para cada característica. Na Fase 3, a partir dos dados vetoriais de nível estático da água subterrânea de cada poço foi realizada a interpolação pelo método IDW (Inverse Distance Weighting), agrupando os valores conforme as cinco classes de profundidade do método e exportando para um novo Raster.

Figura 1. Método GOD para classificar a vulnerabilidade de contaminação de aquíferos

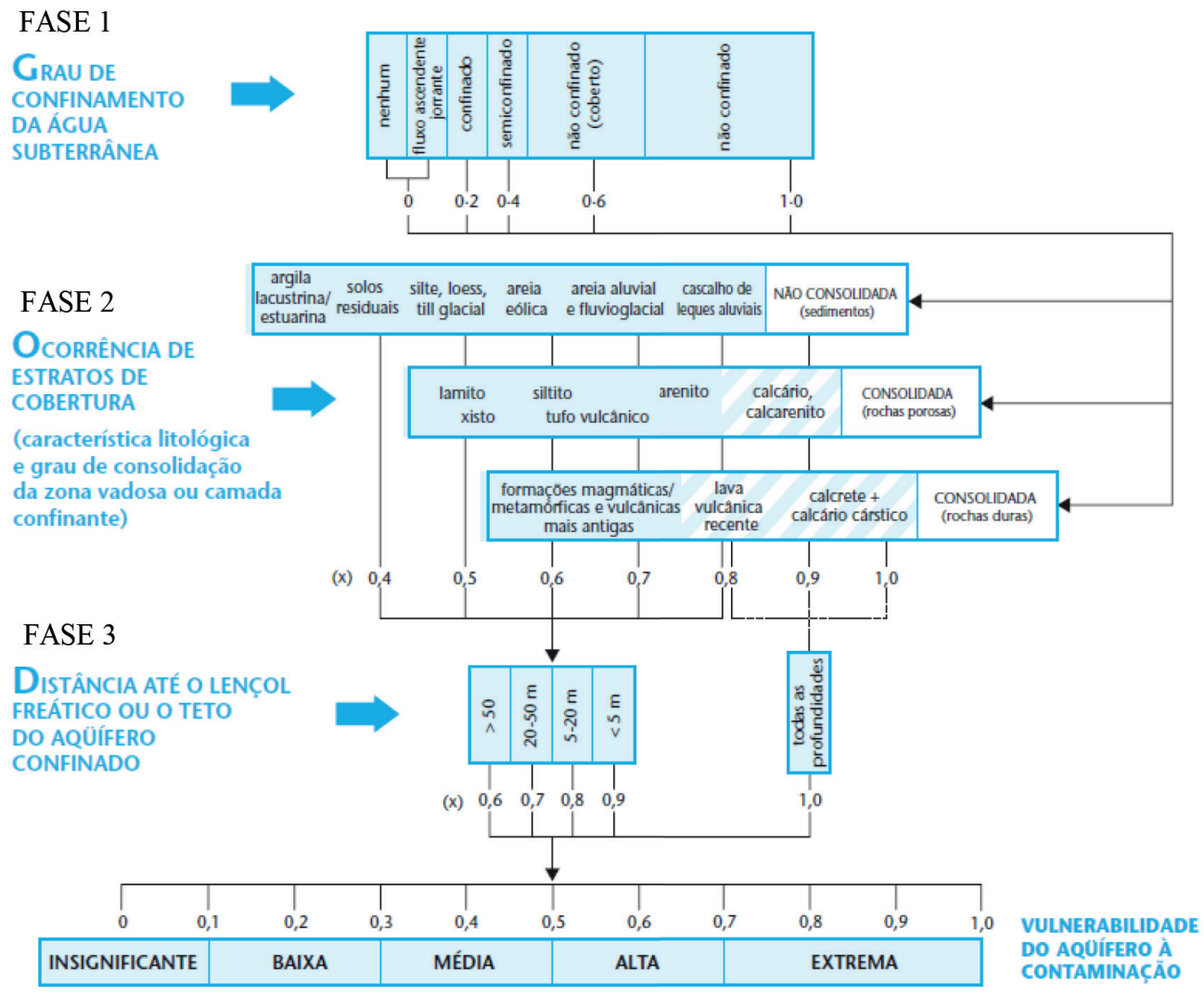

Fonte: Foster et al. (2006). 
Todos os dados foram trabalhados no ArcGIS 10.2.2, cada fase do método GOD foi realizada de forma independente, para, posteriormente, serem cruzadas (multiplicadas) as informações de cada pixel com seu respectivo valor atribuído e gerar o mapa final de vulnerabilidade do aquífero.

\section{Resultados e discussão}

Os estratos geológicos dos poços analisados, que envolvem as características litológicas que influenciaram a formação do solo e o grau de consolidação da zona vadosa, apresentaram duas unidades definidas: Cobertura Supracrustal e o Embasamento Cristalino (TABELA 1), as quais possuem correlação com o ligotipo associado, com a característica do substrato e consequentemente com o grau de vulnerabilidade.

Tabela 1. Classificação das formações geológicas existentes no município de Tucano-BA

\begin{tabular}{|c|c|c|}
\hline Unidade Geológica & Ligotipos & Características \\
\hline Cobertura Supracrustal & $\begin{array}{c}\text { Arenito subarcósio, Carvão, } \\
\text { Folhelho, Siltito }\end{array}$ & $\begin{array}{c}\text { Sedimentar - Intergranular / } \\
\text { Não Confinado }\end{array}$ \\
\hline Cobertura Supracrustal & $\begin{array}{l}\text { Argilito Arenoso, } \\
\text { Arenito Conglomerático }\end{array}$ & $\begin{array}{c}\text { Sedimentar - Intergranular / } \\
\text { Não Confinado }\end{array}$ \\
\hline Cobertura Supracrustal & $\begin{array}{c}\text { Calcilutito, Arenito, } \\
\text { Arenito Conglomerático, Conglomerado }\end{array}$ & $\begin{array}{l}\text { Essencialmente Intergranular } \\
\text { com influência Cárstica / - }\end{array}$ \\
\hline Cobertura Supracrustal & $\begin{array}{c}\text { Conglomerado, Folhelho, Arenito, } \\
\text { Siltito, Silexito }\end{array}$ & $\begin{array}{c}\text { Sedimentar- Intergranular / } \\
\text { Não Confinado }\end{array}$ \\
\hline Cobertura Supracrustal & $\begin{array}{l}\text { Depósitos de areia, } \\
\text { Depósitos de cascalho }\end{array}$ & $\begin{array}{c}\text { Comportamento meio poroso / } \\
\text { Não Confinado }\end{array}$ \\
\hline Cobertura Supracrustal & $\begin{array}{l}\text { Depósitos de argila, } \\
\text { Depósitos de cascalho }\end{array}$ & $\begin{array}{c}\text { Comportamento meio poroso / } \\
\text { Não Confinado }\end{array}$ \\
\hline Embasamento Cristalino & Granodiorito e Granito & Fissural / - \\
\hline Embasamento Cristalino & $\begin{array}{c}\text { Metabasalto, } \\
\text { Formação Ferrífera bandada (Bifs) }\end{array}$ & Fissural / - \\
\hline Cobertura Supracrustal & $\begin{array}{c}\text { Metarenito, Metaconglomerado, } \\
\text { Metachert }\end{array}$ & Fissural / - \\
\hline \multicolumn{3}{|l|}{ Contato entre o Embasamento } \\
\hline $\begin{array}{l}\text { Cristalino e a Cobertura } \\
\text { Supracrustal }\end{array}$ & Metadacito, Metatufo & Fissural / - \\
\hline Contato entre o Embasamento & Migmatito, Kinzigito, & \\
\hline $\begin{array}{l}\text { Cristalino e a Cobertura } \\
\text { Supracrustal }\end{array}$ & Rocha Calcissilicatica, Quartzito & Fissural / - \\
\hline Cobertura Supracrustal & $\begin{array}{l}\text { Siltito, Folhelho Carbonoso, } \\
\text { Calcilutito, Arenito }\end{array}$ & Sedimentar - Intergranular / - \\
\hline Cobertura Supracrustal & $\begin{array}{l}\text { Siltito, Folhelho, Argilito, Arenito } \\
\text { Não Confinado }\end{array}$ & Sedimentar - Intergranular / \\
\hline
\end{tabular}

Fonte: Elaborada pelos autores (2017). 
Ainda pela Tabela 1 se observa que a cobertura supracrustal, a qual está associada à sequência da Formação Marizal da Região de Tucano, é a unidade geológica mais característica da área de recarga da Bacia de Tucano, por ser coberta pelo pacote sedimentar (MESTRINHO et al., 2006) e devido às características do ligotipo, que possui um índice de permeabilidade mais alto, embora tenha uma característica argilosa com pontos locais silto-arenoso, enquanto que no setor do Embasamento Cristalino o índice de permeabilidade é mais baixo, mesmo sendo fraturado, característica esta da própria composição do ligotipo.

O grau de confinamento da água subterrânea tem relação direta com o ciclo deposicional da bacia e com a continuidade lateral das camadas sedimentares, isso indica livre dinâmica vertical e horizontal do fluxo de água nos pontos de recargas mais arenosas que, consequentemente, terão uma permeabilidade mais alta. Nota-se que a água subterrânea na área estudada, em sua maioria, não é confinada, assumindo, portanto, os maiores valores na fase de grau de confinamento (FIGURA 2), enquanto que as regiões de composições geológicas de rochas fissuradas obtiveram os menores valores.

Figura 2. Mapas com os valores atribuídos pelo método GOD para cada fase: confinamento, litologia e profundidade, no município de Tucano-BA
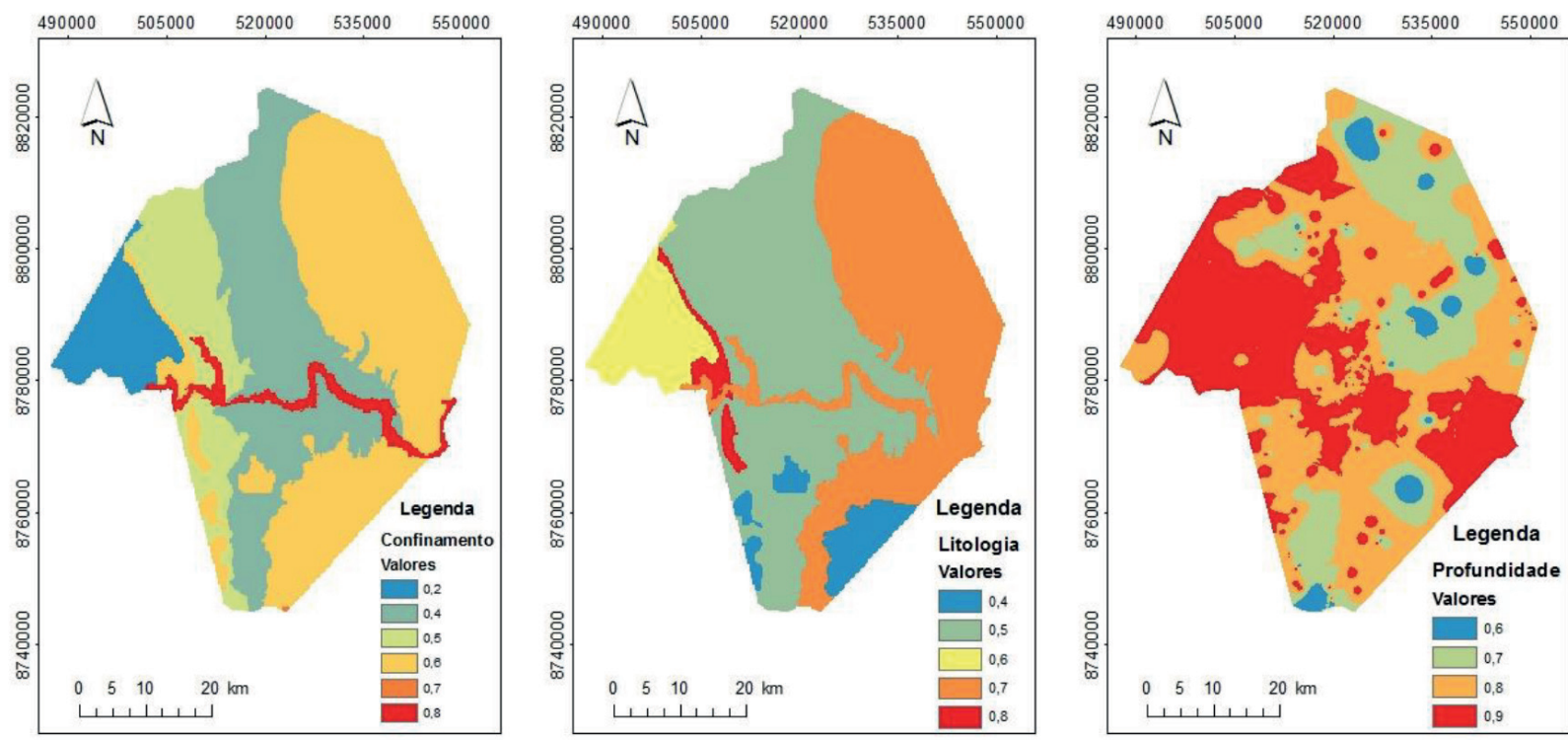

Fonte: Elaborada pelos autores (2017).

Com relação à litologia, em que são considerados os valores das tipologias de texturas e/ou solo e rocha presentes na camada vadosa, localizada acima do nível freático de cada poço, o menor valor $(0,4)$ foi caracterizado pela presença de depósito de argila. Nos poços com presença de sedimentos de arenito, admitiram-se os valores de 0,6 a 0,8, sendo os valores de 0,5 (na porção central da área estudada) o mais representativo, influenciado pela camada argilosa do material litológico. 0 valor 0,7 foi observado em toda região leste, sendo espacialmente significativo na área, indicando a variação da influência da ocorrência dos estratos.

No que se refere aos valores de distância da superfície até o nível estático da água subterrânea, os valores mais representativos foram de 0,8 e 0,9, o que retrata o quão superficial é o aquífero na região estudada, uma vez que o menor valor de 0,6 (profundidade superior a $50 \mathrm{~m}$ ) foi verificado em alguns pontos ao longo de todo o município. 
A partir das análises das três fases do método GOD, observou-se que as águas subterrâneas da área de estudo apresentam expressivamente uma baixa $(71,99 \%)$ e média $(23,79 \%)$ vulnerabilidade (FIGURA 3), com pequenas áreas consideradas insignificantes $(1,28 \%)$ quanto ao risco de contaminação e apenas o trecho referente ao Rio Itapicuru foi apontado como alto (2,94\%), obtendo o valor de 0,504, estando, portanto, no limite da classe de médio para alto e relacionado aos depósitos de areia e de cascalhos. Esse resultado de maior risco de contaminação associado às planícies fluviais foram verificados também por Montero e Peixoto (2013), que observaram os valores extremos de vulnerabilidade ao longo dos Rios Aguapeí e Tibiriça e aconselharam restrições rígidas quanto ao transporte e manuseio de substâncias contaminantes e à implantação de atividades poluidoras próximas a esses rios.

Figura 3. Mapa da vulnerabilidade do aquífero pelo método GOD no município de Tucano-BA

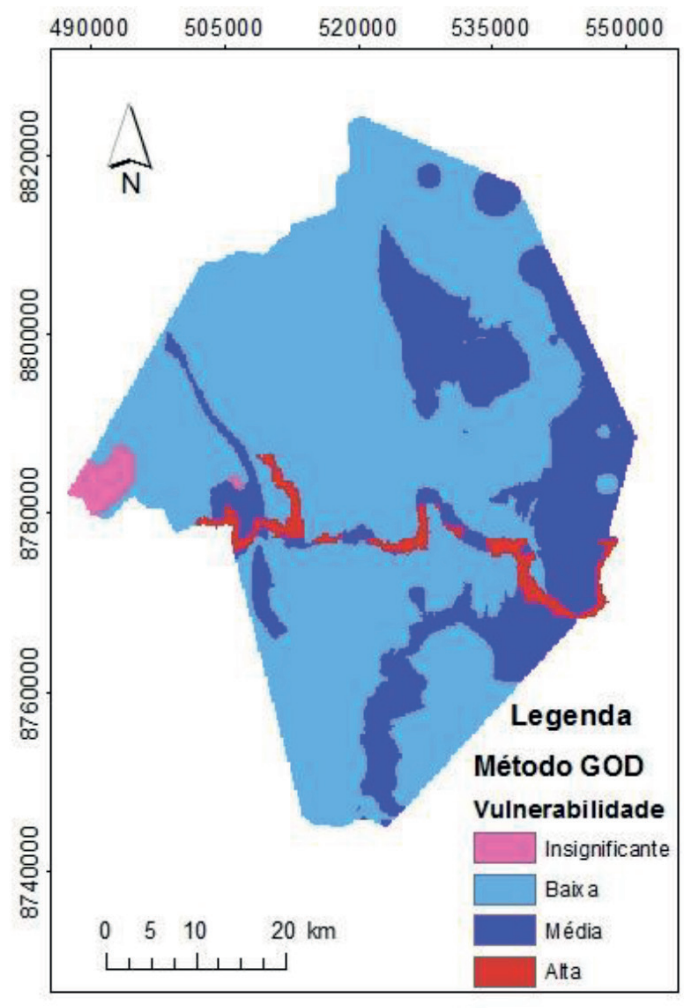

Fonte: Elaborada pelos autores (2017).

O baixo índice de vulnerabilidade para a região de Tucano foi observado também por Mestrinho et al. (2006) ao analisarem o método GOD em toda a extensão da Bacia Hidrográfica do Rio Itapicuru, com valores inferiores a 0,5 proporcionado, segundo os autores, pela presença da bacia sedimentar de Tucano. Porém, os autores não detalham o mapeamento nas águas subterrâneas no município tal como realizado no presente estudo.

Apesar de a Fase 3 indicar águas subterrâneas pouco profundas, o que aumenta o risco de sua contaminação, as demais fases do método GOD (critérios de confinamento e ocorrência litológica) foram condicionantes para classificar a vulnerabilidade da área. Meira et al. (2014) observaram situação semelhante, observando o predomínio da classe de vulnerabilidade moderada em 2/3 da área do aqüífero Guarani, onde há influência do tipo de solo (Argissolo) com alta profundidade do 
lençol freático. A mesma situação ocorreu com o Aquífero Serra Geral, estudado por Reginato e Ahlert (2013). Ambos os aquíferos, com nível freático próximos da superfície, apresentaram respectivamente uma expressiva vulnerabilidade de baixa a média. Porém, no caso do Guarani, as áreas com alto risco ficaram associadas exatamente aos locais de pouca profundidade do aquífero, conferido em associação com os outros componentes do método, enquanto no presente estudo, as altas vulnerabilidades estavam relacionadas à camada arenosa.

Duarte et al. (2016), ao estudarem as águas subterrâneas de Humaitá e Amazonas, constataram uma média e alta vulnerabilidade à contaminação que se deu pelo fato de se tratar de um aquífero livre, com nível estático pouco profundo e que teve a influência da Fase Litológica, a qual tinha como constituintes os sedimentos arenosos da camada vadosa. Por outro lado, Souza et al. (2015) não verificaram alto risco à contaminação mesmo tendo um aquífero livre, superficial com siltes e argilas como estratos de cobertura, os quais conferem menor permeabilidade aos contaminantes.

Existe uma significativa baixa vulnerabilidade de contaminação das águas subterrâneas no município de Tucano e, de acordo com Oliveira et al. (2007), a água subterrânea varia de boa qualidade a uma qualidade aceitável. No entanto, os autores afirmam que há um padrão impróprio dessas águas em áreas próximas ao município, devendo-se, portanto, destacar que os fluxos subterrâneos destas águas provenientes de regiões vizinhas podem prejudicar a qualidade das águas do aquífero, com atenção ao fluxo subterrâneo que tem sua hidrodinâmica preferencial na Bacia do Itapicuru no sentido NW-SE, subordinado, localmente, a um fluxo N-S, em direção à calha do rio, com alinhamento N-S na parte central do domínio sedimentar (região do município de Tucano) (PURIFICAÇÃO et al., 2016).

Portanto, mesmo não havendo altos riscos de vulnerabilidade ambiental das águas subterrâneas no município de Tucano, é importante o constante monitoramento da região de estudo, a fim de reduzir impactos antrópicos que possam favorecer o contato de poluentes às águas dos aquíferos.

\section{Conclusões}

O método GOD permitiu mapear a vulnerabilidade das águas subterrâneas no município de Tucano, indicando um baixo risco de contaminação do aquífero, porém com pontos classificados de médio a insignificante, tendo apenas um índice indicando alta vulnerabilidade na porção do Rio Itapicuru.

A avaliação da potencialidade de contaminação das águas subterrâneas deve ser contínua, até mesmo por outros métodos, a fim de observar diferentes potencialidades dos métodos ou diferenças entre eles, para garantir a manutenção da qualidade dos aquíferos a partir de uma gestão adequada dos recursos hídricos.

\section{Vulnerability of groundwater in the semiarid region of Bahia, municipality of Tucano, by GOD method}

\section{Abstract}

Human activities can promote contamination of aquifers, compromising the quality of groundwater. Therefore, it is important to map the risks of vulnerability of natural environments, and one of the most used methods is the GOD (Groundwater occurrence; Overall aquifer class; 
Depth to groundwater). The present study has the objective of analyzing the vulnerability of aquifers to contamination in the municipality of Tucano, using GOD method. For the study, geological and hydrogeological data from 449 tubular wells obtained from the SIAGAS database (CPRM) were analyzed. G parameter was defined for the majority of the area as an unconfined aquifer, $O$ parameter received values between 0.4 and 0.8 (due to variation of the lithological composition along the area) and $D$ parameter, corresponding to the depth of the static level, was between 0.6 and 0.9 , indicating a superficial water table. The GOD method indicated the occurrence of four classes of vulnerability: insignificant (1.28\%), low (71.99\%), average (23.79\%) and high (2.94\%). It was verified a low to medium vulnerability in most of Tucano territory, indicating low risk of contamination for the aquifer; an index pointing out high vulnerability was found only in the portion of Itapicuru River.

Keywords: Aquifer. Contamination. Geoprocessing.

\section{Referências}

AGÊNCIA NACIONAL DE ÁGUAS (ANA). Atlas Brasil: abastecimento urbano de água, v. 1, 2010. Disponível em: <http://atlas.ana.gov.br/Atlas/downloads/atlas/Resumo\%20Executivo/Atlas\%20Brasil\%20-\%20Volume\%201\%20-\%20Panorama\%20Nacional.pdf>. Acesso em: 03 abr. 2017.

BATISTA, C. S. P.; GESUALDO, G. C.; LEITE, P. C. C.; LASTORIA, G.; GABAS, S. G.; CAVAZZANA, G. H.; CASADEI, J. M.; AZOIA, T. S. Aplicação do método GOD para avaliação de vulnerabilidade de aquífero livre em bacia hidrográfica. Águas Subterrâneas, 2016, p. 1-14. Suplemento XIX Congresso Brasileiro de Águas Subterrâneas.

COMPANHIA DE RECURSOS MINERAIS (CPRM). Serviço Geológico do Brasil. Disponível em: <http://www.cprm.gov.br/>. Acesso em: 03 abr. 2017.

DUARTE, M. L.; ZANCHI, F. B.; NEVES, J. R. D.; COSTA, H. S.; JORDÃO, W. H. C. Vulnerabilidade à contaminação das águas subterrâneas no município de Humaitá, Amazonas, Brasil. Revista Ambiente \& Água, v. 11, n. 2, p. 402-413, 2016. Disponível em: <http://dx.doi.org/10.4136/ambi-agua.1797>. Acesso em: 28 abr. 2017.

EMPRESA BRASILEIRA DE PESQUISA AGROPECUÁRIA. EMBRAPA SOLOS. UEP Recife, 2006.

FERON, G. L.; REGINATO, P. A. R. Avaliação da vulnerabilidade de aquíferos localizados na região central de Canoas-RS. Águas Subterrâneas, v. 28, n. 2, p. 1-13, 2014. Disponível em: <https://doi. org/10.14295/ras.v28i2.27866 >. Acesso em: 28 abr. 2017.

FOSTER, S.; HIRATA, R.; GOMES, D.; D’ELIA, M.; PARIS, M. Proteção da Qualidade da Água Subterrânea: um guia para empresas de abastecimento de água, órgãos municipais e agências ambientais. Servmar: Washington, D.C., 2006, p. 1-114.

INSTITUTO DO MEIO AMBIENTE E RECURSOS HÍDRICOS (INEMA). CBH Itapicuru. Disponível em: <http://www.inema.ba.gov.br/gestao-2/comites-de-bacias/comites/cbh-itapicuru/>. Acesso em: 03 abr. 2017. 
MARQUEZAN, R. G. Análise de recursos digitais como ferramentas de avaliação em ações de proteção de aqǘ́feros no trajeto de oleodutos. 2008. 184f. Tese (Doutorado) - Instituto de Pesquisas Hidráulicas, Universidade Federal do Rio Grande do Sul, Porto Alegre, 2008.

MEIRA, J. R.; DE-CAMPOS, A. B.; PEREIRA, L. C. Vulnerabilidade natural e perigo à contaminação de zona de recarga do Aquífero Guarani. Água Subterrâneas, v. 28, n. 1, p. 31-46, 2014. Disponível em: <https://aguassubterraneas.abas.org/asubterraneas/article/viewFile/27412/18080>. Acesso em: 10 abr. 2017.

MESTRINHO, S. S. P.; LUZ, J. A. G. da; PORCIÚnCULA, D. C. L. da. Análise da vulnerabilidade intrínseca das águas subterrâneas na Bacia do Rio Itapicuru, Bahia. Águas Subterrâneas, 2016, p. 1-20. Suplemento XIV Congresso Brasileiro de Águas Subterrâneas.

MONTERO, R. C.; PEIXOTO, A. S. P. Vulnerabilidade e perigo de contaminação dos aquíferos no Alto Aguapeí e Alto Peixe, SP. Ciência \& Engenharia, v. 22, n. 1, p. 115-124, 2013. DOI: http://dx.doi. org/10.14393/19834071.2013.22499.

OLIVEIRA, I. B. de; NEGRÃO, F. R.; SILVA, A. G. L. S. Mapeamento dos aquíferos do estado da Bahia utilizando o índice de qualidade natural das águas subterrâneas-IQNAS. Águas Subterrâneas, v. 21, n. 1, p. 123-137, 2007. Disponível em: < https://aguassubterraneas.abas.org/asubterraneas/article/ viewFile/16176/10695>. Acesso em: 10 abr. 2017.

PURIFICAÇÃO, C. G. C. da; SOARES, R. S.; JESUS, M. H. de; SALLES, L. Q.; GONÇALVES, T. S. Hidrogeologia da Bacia Hidrográfica do Rio Itapicurú-BA, como subsidio para o plano diretor de bacias. Água Subterrâneas, 2016, p. 1-20. Suplemento XIX Congresso Brasileiro de Águas Subterrâneas.

REGINATO, P. A. R.; AHLERT, S. Vulnerabilidade do sistema aquífero Serra Geral na região nordeste do estado do Rio Grande Do Sul. Águas Subterrâneas, v. 27, n. 2, p. 32-46, 2013. Disponível em: < https://aguassubterraneas.abas.org/asubterraneas/article/view/27060 > . Acesso em: 11 abr. 2017.

RIBEIRO, D. M.; ROCHA, W. F.; GARCIA, A. J. V. Vulnerabilidade natural à contaminação dos aquíferos da sub-bacia do Rio Siriri, Sergipe. Águas Subterrâneas, v. 25, n. 1, p. 91-102, 2011. Disponível em: <https://aguassubterraneas.abas.org/asubterraneas/article/viewFile/19366/17666>. Acesso em: 11 abr. 2017.

SABADINI, S. C.; RUCHKYS, U. A.; VELÁSQUEZ, L. N. M.; TAYER, T. de C. Potencial de vulnerabilidade natural de aquíferos à contaminação no quadrilátero ferrífero, Minas Gerais e sua relação com a atividade minerária de ouro. Caderno de Geografia, v. 27, n. 49, p. 340-352, 2017. Disponível em: < https://doi.org/10.5752/p.2318-2962.2017v27n49p340>. Acesso em: 10 abr. 2017.

SANTOS, A. C. B. dos; MENDES, R. L. R.; SILVA, G. N.; TAVARES, A. N. Vulnerabilidade de aquíferos: uma análise da aplicação do método GOD com a base de dados SIAGAS. Água Subterrâneas, 2013, p. 1-4. Suplemento III Congresso Internacional de Meio Ambiente Subterrâneo.

SISTEMA DE INFORMAÇÕES DE ÁGUAS SUBTERRÂNEAS (SIAGAS). Disponível em: <http://siagasweb.cprm.gov.br/layout/>. Acesso em: 05 dez 2016. 
SOUZA, V. C. A. B.; SOARES, V. P.; MACIEL, A. V.; KEMERICH, P. D. C. Qualidade da água subterrânea do bairro Perpétuo Socorro de Santa Maria-RS. Disciplinarum Scientia. Série: Ciências Naturais e Tecnológicas, v. 5, n. 1, p. 31-49, 2004. Disponível em: <https://periodicos.ufn.edu.br/index.php/ disciplinarumNT/article/view/1188>. Acesso em: 10 abr. 2017.

SOUZA, M. C. B.; MONTEIRO, C. A. B.; CASTRO, M. A. H. de. O uso da avaliação do perigo de contaminação do aquífero como um requisito para o licenciamento ambiental de cemitérios. Brazilian Geographical Journal: Geosciences and Humanities research medium, v. 6, n. 2, p. 137-153, 2015. Disponível em: <http://www.seer.ufu.br/index.php/braziliangeojournal/article/view/29355/18076>. Acesso em: 05 abr. 2017.

TERRA, L. G.; LÖBLER, C. A.; SILVA, J. L. S. da. Estimativa da vulnerabilidade à contaminação dos recursos hídricos subterrâneos do município de Santiago-RS. Revista Eletrônica em Gestão, Educação e Tecnologia Ambiental, v. 10, n. 10, p. 2208-2218, 2013. DOI: http://dx.doi. org/10.5902/223611707887.

VIEIRA, Â. T.; MELO, F.; LOPES, H. B. V.; CAMPOS, J. C. V.; BOMFIM, L. F. C.; COUTO, P. A. A.; BEVENUTI, S. M. P. Projeto Cadastro de Fontes de Abastecimento por Água Subterrânea. Salvador: CPRM/PRODEEM, 2005, p. 1-36.

\section{Histórico editorial}

Submetido em: 02/09/2017

Aceito em: 29/11/2017 